aged wasps. Some of these alternative pollinators are managed, at a much smaller scale, which itself is risky because rare events - such as disease or environmental change - are more likely to wipe out small populations than large ones. Other domesticated plant species rely exclusively on native bats or birds, whose fate is linked to habitat destruction.

Changes in abundance have been monitored for only a small fraction of the species known to be effective pollinators; there is a growing list of factors implicated in population declines. In the United States, honeybee colonies have more than halved since 1947 (from 5.5 million to 2.4 million). Parasitic mites and pathogens, insecticides used to control crop pests and displacement by Africanized honeybees, are all to blame and may also affect managed populations of non-Apis pollinators. Toxic effects of secondary compounds produced by genetically engineered plants are suspected. Habitat modification is probably still the prime culprit in the decline or endangered status of several species of wild pollinators.

A sustained pollinator decline in North America, for example, would mean lower yields from crops that depend on animals for pollination, and so prices would increase; or there would be less variety available as farmers switch from growing insect-pollinated crops to the restricted range of self-fertilizing ones that give reliable fruit or grain production.

Farmers have known for centuries what the public and legislators may be accepting just in time: a field of crops without pollinators is a harbinger of a greater calamity. Status of Pollinators offers a host of straightforward and complementary recommendations to help prevent crop failures and the collapse of native plant communities. There isn't a silver bullet to zap the problem: simultaneous application of a variety of solutions will be necessary to sustain a healthy and diverse community of pollinators nationwide.

For example, we need more research entomologists, plant-population biologists, geneticists, agricultural ecologists and systematists. To identify regions vulnerable to pollination failure, we should run international pollinatormonitoring programmes. For long-term pollinator security, Mexico, Canada and the United States should pursue collaborative breeding programmes to identify and manage pollinators other than Apis. Land-use practices friendly to pollinators should be adopted by industrial, public and residential landowners. Educational institutions should promote awareness of the intimate connection between plants, their pollinators, our diets and our economy.

In the United States, only a continent-wide commitment to the protection of pollinators will allow future generations to enjoy the fruits of their labour.

Susan J. Mazer is professor in the Department of Ecology and Evolution, University of California, Santa Barbara, California 93106, USA.

\title{
Glitter bugs
}

Nick Thomas

A pile of dead insects and an assortment of disassembled antiquewatch mechanisms would probably be destined for the rubbish heap in most homes. In the pretty coastal town of South

Portland, Maine, a young artist combines biology and technology to create bioart sculptures (www. insectlabstudio.com).

Artistic inspiration - he refers to it as his 'epiphany' - first struck Mike Libby in the late 1990s. He happened on a particularly colourful beetle lying dead beside a vending machine. Months later, he assembled his first gear-laden insect from the salvaged workings of an old Mickey Mouse watch, which he transplanted into the beetle.

Libby calls his blending of nature and technology "a celebration of natural and man-made function". He collects local insects such as butterflies, dragonflies and beetles, but many of his specimens now come from companies that supply insect collectors and entomologists, enabling him to adapt his art

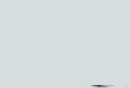

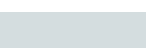

$$
\text { . }
$$
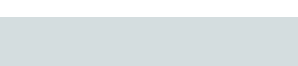

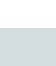

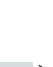

